\title{
Modified Graphite Paste Electrode with Strontium Phen-Dione Complex for Simultaneous Determination of a Ternary Mixture of Dopamine, Acetaminophen and Xanthine. Part II
}

\author{
M. Shahbakhsh", S.Narouie, Z. Hashemzaei, A. Nouri, H. Saravani and M. Noroozifar* \\ Analytical Research Laboratory, Department of Chemistry, University of Sistan and Baluchestan, \\ Zahedan, P.O. Box 98135-674, Iran \\ *E-mail: Mahdi.shah2011@yahoo.com, mnoroozifar@chem.usb.ac.ir
}

doi: $10.20964 / 2017.12 .56$

Received: 31 August 2017 / Accepted: 3 October 2017 / Published: 12 November 2017

\begin{abstract}
In this study, modified graphite paste electrode with $\left.\left[\mathrm{Sr}\left(\mathrm{OH}_{2}\right)_{4} \text { (phen-dione }\right)_{2}\right](\mathrm{Cl})_{2}$ complex (Sr-Phen) was used for simultaneous electrochemical determination of dopamine (DA), acetaminophen (AC), and xanthine $(\mathrm{XN})$. The proposed modified electrode was shown a sensitive and selective response for simultaneous determination of DA, AC and $\mathrm{XN}$ to three well-separated peaks in the potential range from 0.4 to $1.1 \mathrm{~V}$ using CV and DPV methods in a phosphate buffer solution with pH 3.0. Some kinetic and thermodynamic parameters for the electrochemical oxidation of DA, AC, and XN were also determined. Under the optimum conditions the calibration curves were linear up to 220, 150 and 60 $\mu \mathrm{M}$ with a theoretical detection limits $(\mathrm{S} / \mathrm{N}=3)$ of 800,90 and $60 \mathrm{nM}$ for $\mathrm{DA}, \mathrm{AC}$, and $\mathrm{XN}$, respectively. Moreover, GPE/Sr-Phen were successfully used to determine DA, AC, and XN in human urine and blood serum samples.
\end{abstract}

Keywords: Strontium Phen-dione, Simultaneous determination, Dopamine, Acetaminophen, Xanthine.

\section{FULL TEXT}

(C) 2017 The Authors. Published by ESG (www.electrochemsci.org). This article is an open access article distributed under the terms and conditions of the Creative Commons Attribution license (http://creativecommons.org/licenses/by/4.0/). 